Published in final edited form as:

Eur J Nutr. 2018 February ; 57(1): 107-117. doi:10.1007/s00394-016-1301-2.

\title{
Pre-pregnancy caffeine and caffeinated beverage intake and risk of spontaneous abortion
}

\author{
Audrey J. Gaskins, Sc.D. ${ }^{1}$, Janet W. Rich-Edwards, Sc.D. ${ }^{2,3,4}$, Paige L. Williams, Ph.D. ${ }^{2,5}$, \\ Thomas L. Toth, M.D. ${ }^{6}$, Stacey A. Missmer, Sc.D. ${ }^{2,3,7,8}$, and Jorge E. Chavarro, M.D., Sc.D. \\ $1,2,3$ \\ ${ }^{1}$ Department of Nutrition, Harvard T.H. Chan School of Public Health, Boston, Massachusetts \\ 2Department of Epidemiology, Harvard T.H. Chan School of Public Health, Boston, \\ Massachusetts \\ ${ }^{3}$ Channing Division of Network Medicine, Department of Medicine, Brigham and Women's \\ Hospital and Harvard Medical School, Boston, Massachusetts \\ ${ }^{4}$ Connors Center for Women's Health and Gender Biology, Department of Medicine, Brigham and \\ Women's Hospital and Harvard Medical School, Boston, Massachusetts \\ ${ }^{5}$ Department of Biostatistics, Harvard T.H. Chan School of Public Health, Boston, Massachusetts \\ ${ }^{6}$ Vincent Obstetrics and Gynecology, Massachusetts General Hospital and Harvard Medical \\ School, Boston, Massachusetts \\ ${ }^{7}$ Department of Obstetrics, Gynecology and Reproductive Biology, Beth Israel Deaconess \\ Medical Center and Harvard Medical School, Boston, Massachusetts \\ ${ }^{8}$ Department of Obstetrics, Gynecology and Reproductive Biology, Brigham and Women's \\ Hospital and Harvard Medical School, Boston, Massachusetts
}

\begin{abstract}
Purpose-To investigate the relation between pre-pregnancy caffeine and caffeinated beverage intake and risk of spontaneous abortion (SAB).

Methods-Our prospective cohort study included 15,590 pregnancies from 11,072 women with no history of SAB in the Nurses' Health Study II (1991-2009). Beverage intake was assessed every 4 years using a validated questionnaire. Pregnancies were self-reported with case pregnancies lost spontaneously at $<20$ weeks gestation. Multivariable log-binomial regression models with generalized estimating equations were used to estimate the relative risks (RRs) and 95\% confidence intervals (CIs).
\end{abstract}

Results-There was a positive linear trend across categories of pre-pregnancy caffeine intake and risk of SAB such that women consuming $>400 \mathrm{mg} /$ day had $1.11(95 \% \mathrm{CI} 0.98,1.25)$ times the risk of SAB compared to women consuming $<50 \mathrm{mg} /$ day ( $\mathrm{p}$-trend=0.05). Total coffee intake had a

Corresponding Author: Audrey J. Gaskins, Harvard T.H. Chan School of Public Health, Building II 3rd Floor, 655 Huntington Ave, Boston, MA 02115, Tel: (704) 737-3314, agaskins@hsph.harvard.edu.

Conflict of Interest Statement. On behalf of all authors, the corresponding author states that there is no conflict of interest. 
positive, linear association with SAB. Compared to women with no pre-pregnancy coffee intake, women consuming $\geq 4$ servings/day had a $20 \%(6,36 \%)$ increased risk of SAB ( $P$-trend $=0.01)$. There was no difference in the association between caffeinated and decaffeinated coffee and risk of SAB. Pre-pregnancy intake of caffeinated tea, caffeinated soda, and decaffeinated soda had no association with SAB.

Conclusions-Pre-pregnancy coffee consumption at levels $\geq 4$ servings/day is associated with increased risk of SAB, particularly at weeks 8-19.

\section{Keywords}

caffeine; coffee; miscarriage; pregnancy; spontaneous abortion

\section{Introduction}

Studies on maternal caffeine consumption and risk of spontaneous abortion (SAB) have been conducted since the 1980s and stands as the most heavily researched dietary factor in regards to pregnancy outcomes. While a recent meta-analysis concluded that for every 100 $\mathrm{mg}$ /day increment in maternal consumption of caffeine during early pregnancy, the risk of SAB increased by $14 \%$ [1], the evidence on pre-pregnancy consumption of caffeine and risk of pregnancy loss is less clear. As the majority of pregnancy losses occur very early in gestation, pre-pregnancy caffeine consumption is of research interest as this may be a relevant time window of exposure for these early losses.

Many previous studies on pre-pregnancy caffeine intake and miscarriage have enrolled women during early pregnancy and inquired about caffeine intake retrospectively prior to the interview [2-5], raising concerns about differential left truncation and recall biases. Out of the 5 studies that have enrolled women prior to pregnancy, three have been limited by small sample sizes ( $\mathrm{n}=171,575$, and 113) [6-8]. While the two other studies were much larger, the generalizability of their results to the US population is questionable $[9,10]$. Specifically, the Tolstrup et al. study from Denmark included 1,381 pregnancies but recorded a mean daily caffeine intake of almost $500 \mathrm{mg}$ (more than twice the average intake of American woman [11]) and $<1 \%$ of their women reported no coffee consumption [9]. The Hahn et al. study, also from Denmark, involved 5,132 women [10], but only included pregnancy planners, raising questions about generalizability given that than half of pregnancies in the US are unplanned [12] and the known links between pre-pregnancy health behaviors, pregnancy intention and pregnancy outcomes $[13,14]$.

Therefore, we sought to expand on the existing research by evaluating the association of prepregnancy caffeine and caffeinated and decaffeinated beverage intake with spontaneous abortion in a large, prospective cohort of women in the United States.

\section{Methods}

\section{Study Population}

We used data from the Nurses' Health Study II (NHS2), an ongoing prospective cohort of 116,480 female nurses, ages 24 to 44 years at the study's inception in 1989. Questionnaires 
are distributed every 2 years to update lifestyle and medical characteristics and to capture incident health outcomes. Diet was first assessed in 1991 and has been updated every 4 years thereafter. Response rates for each questionnaire cycle have exceeded $90 \%$. Women were eligible for this analysis if they had no history of pregnancy loss in 1991 and reported at least one pregnancy during 1992-2009. Participants contributed eligible pregnancies until their first pregnancy loss or the end of follow-up. Women were censored after their first pregnancy loss to avoid reverse causation bias resulting from behavioral changes which may occur after experiencing an adverse outcome. Of the 19,451 eligible pregnancies, we excluded from the analysis those with missing data on diet $(n=2,475)$, implausible or missing gestational age $(n=111)$, missing year of pregnancy $(n=619)$, as well as those among women with a diagnosis of type II diabetes $(n=69)$, cardiovascular disease $(n=86)$, or cancer $(n=141)$ prior to the pregnancy (Supplemental Figure 1). The excluded women did not differ substantially in age, BMI, parity, smoking status, race, history of infertility, and cumulative incidence of spontaneous abortion compared to included women. The final sample consisted of 15,950 pregnancies from 11,072 women. This study was approved by the institutional review board of the Partners Health Care System, Boston, Massachusetts, with the participants' consent implied by the return of the questionnaires.

\section{Caffeine Assessment}

Diet was evaluated using a validated 131-item food frequency questionnaire (FFQ) $[15,16]$. Women were asked to report how often, on average, they consumed specified amounts of each food and beverage included in the questionnaire during the previous year. There were 9 response options ranging from "none or less than $1 /$ month" to " $6+/$ day". The nutrient content and portion size of each item is obtained from a nutrient database derived from the US Department of Agriculture and additional information from manufacturers [17]. Specific caffeine-containing items were caffeinated coffee (137 mg caffeine/cup) and tea (47 mg caffeine/cup), caffeinated sodas (46 mg caffeine/bottle or can) and chocolate ( $7 \mathrm{mg}$ caffeine/ serving). We calculated the total intake of caffeine by summing the caffeine content for specific items multiplied by weights proportional to the frequency of use. In a similar population of nurses, high correlations were found between caffeinated beverage intakes assessed with the FFQ and four 1-week diet records collected over 1 year (coffee: 0.78, tea: 0.93, and soda: 0.84) [16,18]. To maintain a prospective analysis, diet information from 1991 was related to pregnancies in 1992 to 1995 ; the 1995 diet information was used for pregnancies in 1996 to 1999; and so forth. If a woman was missing the most recent diet questionnaire prior to her pregnancy ( $<5 \%$ of women), the most recent previous dietary data was carried forward.

\section{Outcome Assessment}

Women were asked to report their pregnancies at study enrollment and in each biennial follow-up questionnaire. On the 2009 questionnaire, women also reported information on the year, length, complications, and outcomes of all previous pregnancies. Options for pregnancy outcomes were a singleton live birth, multiple birth, miscarriage or stillbirth, tubal or ectopic pregnancy, or induced abortion. Gestational lengths were reported in categories: <8 weeks, 8-11 weeks, 12-19 weeks, 20-27 weeks, 28-31 weeks, 32-36 weeks, 37-39 weeks, 40-42 weeks, and $\geq 43$ weeks gestation. Self-reported pregnancy outcome and 
gestation length have been previously found to be validly reported [19]. Spontaneous abortion was defined as a spontaneous loss occurring before 20 completed weeks gestation. We also considered early- to mid-first trimester losses ( $<8$ weeks), late-first trimester losses (8-11 weeks), early second trimester losses (12-19 weeks), and stillbirths ( 220 weeks) as separate outcomes. The validity of maternal recall of pregnancy loss has not been assessed in this population; however the sensitivity of reporting a loss is estimated to be around $75 \%$ $[20,21]$. In the validation study by Wilcox et al., it was shown that the accuracy of report depends greatly on the gestational age at the time of SAB (accuracy was 54\% at $<7$ weeks vs. $93 \%$ at $>13$ weeks) and on the length of time since SAB (accuracy was $82 \%, 79 \%$, and $73 \%$ for $\mathrm{SABs}$ occurring $<10,10-19$, and $\geq 20$ years ago) [20]. The comparison group for our analyses was all pregnancies that did not end in SAB (live births [ $\mathrm{n}=12,298]$, induced abortions [ $n=634]$, or tubal/ectopic pregnancies [ $n=142]$ ).

\section{Covariate Assessment}

Information on potential confounding variables was assessed at baseline and during followup. For variables that were updated over follow-up, the most recent value prior to pregnancy was used. Maternal age was computed as the difference between year of birth and the year of pregnancy. Weight, smoking status, multivitamin use, hormonal contraceptive use, duration of rotating night shift work, and history of infertility were self-reported at baseline and updated every two years thereafter. Race and height were reported in 1989. Pre-pregnancy body mass index (BMI) was calculated as self-reported weight in kilograms divided by selfreported height in meters squared. In a previous validation study, self-reported weight was highly correlated with weight measured by a technician among a similar group of nurses $(\mathrm{r}=0.97)[22]$. Physical activity was ascertained in 1991, 1997, 2001, and 2005 using a validated questionnaire [23], from which metabolic equivalent task-hours per week were derived. History of ovulation inducing medication use was self-reported starting in 1993 and updated every 2 years. Marital status was reported in 1989, 1993, and 1997. Employment outside the home was assessed in 1989, 1993, and 2001.

\section{Statistical Analysis}

Baseline characteristics were derived from the 1991 questionnaire for all women contributing eligible pregnancies and differences in baseline characteristics by prepregnancy caffeine intake were compared. Overall caffeine intake was analyzed as a continuous exposure and as categories based on predetermined cutoffs. Pre-pregnancy intake of caffeinated and decaffeinated beverages was categorized according to the distribution in the cohort.

The relative risk (RR) of SAB in relation to pre-pregnancy caffeine and beverage intake was estimated using log-binomial regression. Generalized estimating equations with an exchangeable working correlation structure were used to account for the within-person correlation between pregnancies. For the primary analysis, we examined the relation between the continuous measure of caffeine intake and risk of SAB non-parametrically with restricted cubic splines [24]. Tests for non-linearity used the likelihood ratio test, comparing the model with only the linear term to the model with the linear and the cubic spline terms. For all other analyses, the RR was computed as the risk of SAB in a specific category 
compared with the risk in the lowest caffeine or caffeinated beverage intake category. Tests for linear trend across categories were conducted by using the median values in each category as a continuous variable. In addition to age, calorie, and year adjusted models, multivariable models were further adjusted for a priori selected pre-pregnancy covariables. These included BMI, smoking status, physical activity, history of infertility, marital status, employment outside the home, duration of rotating shift work, race, alcohol intake, and supplemental folate intake. All caffeinated beverages were also further adjusted for one another. Decaffeinated beverages were further adjusted for caffeinated coffee intake. Fullyadjusted models were run both with and without adjusting for nulliparity since adjusting for reproductive history might lead to overadjustment [25,26]. Categorical covariables included an indicator for missing data, if necessary.

To assess the robustness of our findings, we investigated whether the relation of prepregnancy caffeine and beverage intake with SAB differed by gestational age at loss. We also performed an analysis restricted to pregnancies from women who never smoked to address the potential of residual confounding by smoking. To minimize uncontrolled confounding by behaviors related to pregnancy planning and recognition, we restricted analyses to married women not using hormonal contraception [27,28]. Last, to address the potential of misclassification of exposure due to the interval between diet assessments, we restricted analyses to pregnancies in 1992,1996, 2000, and 2004, the years closest to diet assessment and we performed an analysis where we did not carry forward previous diet data if the most recent diet data was missing.

\section{Results}

Overall 11,072 women met our inclusion criteria, contributing 15,950 pregnancies to this analysis during 18 years of follow-up. The cumulative risk of pregnancy loss in our cohort was $6.3 \%$ by week $7,13.6 \%$ by week $11,17.3 \%$ by week 20 , and $18.0 \%$ by week $43+$. On average, women in our cohort consumed $184 \mathrm{mg} /$ day of caffeine. The biggest contributor to pre-pregnancy caffeine intake was caffeinated coffee (71\%), followed by caffeinated tea (14\%), caffeinated soda (12\%), and chocolate (3\%). In 1991, the most common method of preparing caffeinated and decaffeinated coffee was filtered $(81 \%$ and $66 \%)$ followed by instant (8\% and $16 \%)$ and espresso or percolator (5\% and 3\%).

Women consuming the highest amounts of caffeine were, on average, slightly older and of higher BMI, more likely white, nulliparous, employed outside the home, and to have worked rotating night shifts in the past 2 years (Table 1). Women with higher caffeine intake were also less likely to be never smokers and never oral contraceptive users. Women consuming the highest amounts of caffeine were less likely to consume a multivitamin, had higher intake of calories, fat, and alcohol, and had lower intake of carbohydrates, protein, and folate.

The association between pre-pregnancy caffeine intake and risk of spontaneous abortion showed suggestive evidence of a non-linear association ( $P$-value for non-linearity $=0.06)$, but this was primarily driven by associations with losses at $<8$ weeks ( $P$-value for nonlinearity $=0.004$ ) and the association with losses at 8-11 weeks and 12-19 weeks appeared 
linear ( $P$-value for non-linearity $=0.50$ and 0.53 , respectively). When caffeine intake was categorized, there was a positive linear trend across categories of pre-pregnancy caffeine intake and risk of SAB such that women consuming $>400 \mathrm{mg} /$ day had 1.11 (95\% CI 0.98, 1.25 ) times the risk of $\mathrm{SAB}$ compared to women consuming $<50 \mathrm{mg} /$ day (p-trend $=0.05$ ) (Table 2).When specific beverages were examined, there was a positive, linear association between pre-pregnancy coffee intake and risk of SAB. The adjusted RR $(95 \% \mathrm{CI})$ for $<1,1$, $2-3$, and $\geq 4$ servings/day was $1.02(0.92,1.14), 1.11(0.99,1.24), 1.09(1.00,1.19)$, and 1.20 $(1.06,1.36)$, respectively, compared to women consuming none $(P$-trend $=0.004)$. This translated into an adjusted absolute difference in SAB risk of 3.6\% (95\% CI 1.0, 6.2\%) comparing women consuming $\geq 4$ servings/day to women consuming none. This association became slightly attenuated after adjustment for pre-pregnancy caffeine intake ( $P$-trend for coffee $=0.06)$; however caffeine intake was not associated with SAB in this model $(P=0.77)$. The adjusted RR $(95 \% \mathrm{CI})$ with further adjustment for caffeine was $1.02(0.91,1.14), 1.11$ $(0.99,1.24), 1.09(0.98,1.20)$, and $1.18(1.00,1.40)$ for women consuming $<1,1,2-3$, and $\geq 4$ servings/day of coffee, respectively, compared to women consuming none.

Both caffeinated and decaffeinated coffee intake had a positive association with SAB ( $P$ trend $=0.01$ and 0.04 , respectively) (Table 2 ). When these exposures were included in the same multivariate model, there was no significant difference in the effect of a one serving/day increase on risk of $\mathrm{SAB}$ as the relative risks for caffeinated and decaffeinated coffee were almost identical (RR for caffeinated coffee: 1.04 (1.01, 1.06); RR for decaffeinated coffee: $1.04(0.99,1.09)$; $P$-for-comparison=0.97). Pre-pregnancy intake of other caffeinated beverages such as caffeinated tea and soda and decaffeinated soda had no association with risk of SAB.

Overall, while there was no clear linear association between pre-pregnancy caffeine intake and $\mathrm{SAB}$ at $<8$ or $8-11$ weeks gestation, there was a positive linear association between prepregnancy caffeine intake and SAB at 12-19 weeks gestation (Table 3). This appeared to be driven by caffeinated coffee intake which had a positive association with SAB at 8-11 and $12-19$ weeks gestation but not at $<8$ weeks gestation. The associations between caffeinated tea, caffeinated soda, decaffeinated coffee, and decaffeinated soda and pregnancy loss were non-significant across all time points (Table 3 and Supplemental Table 1). There were no associations between pre-pregnancy caffeine or beverage intake and risk of stillbirth.

In our sensitivity analyses, the magnitude of association between total and decaffeinated coffee remained relatively consistent (Supplemental Table 2); however there was little relation between pre-pregnancy caffeine intake and $\mathrm{SAB}$. The positive association between pre-pregnancy caffeinated coffee intake and $\mathrm{SAB}$ persisted when analyses were restricted to never smokers, the most likely pregnancy planners, and with no diet update but became attenuated when analyses were restricted to pregnancies in the years following dietary assessment.

\section{Discussion}

In our study, women who consumed $\geq 4$ servings/day of coffee prior to pregnancy had a $3.6 \%$ higher absolute risk of SAB compared to woman consuming none. This association 
was driven by losses occurring at 8-19 weeks gestation. Both pre-pregnancy caffeinated and decaffeinated coffee intake were associated with risk of SAB, suggesting that some component in coffee other than caffeine was driving this relationship. Moreover, none of the other caffeinated beverages, including tea and soda, were associated with risk of SAB. The increased risk of SAB at high levels of caffeine intake (e.g. $>400 \mathrm{mg} /$ day) appeared to be driven by pre-pregnancy caffeinated coffee intake; however this association was hard to disentangle given the high correlation between caffeine and coffee intake in this population.

Previous studies on pre-pregnancy caffeine or coffee intake and risk of SAB are summarized in Supplemental Table 3. Overall, the majority of previous studies found an increased risk of SAB comparing women in the highest versus lowest category of pre-pregnancy caffeine intake although the magnitude of these effects varied and many were not statistically significant. Moreover, in a sub-analysis of a recent meta-analysis, the association between pre-pregnancy caffeine intake and pregnancy loss was not statistically significant $(\mathrm{RR}=1.02$, $95 \%$ CI 0.97, 1.07) [29]. Our results suggesting an increased risk of SAB at high levels of caffeine intake (e.g. $>400 \mathrm{mg} /$ day) are consistent with the most recent study which found a relative risk of 1.10 ( $95 \%$ CI $0.91,1.32$ ) comparing women consuming $>300 \mathrm{mg} / \mathrm{day}$ to $<100 \mathrm{mg} /$ day. Moreover, women in their study with a preconception coffee intake $>3$ servings/day had 1.23 (95\% CI 0.91, 1.65) times the risk of SAB compared to women consuming none which was similar to our estimate of 1.20 (95\% CI 1.03, 1.41) for women consuming $\geq 4$ servings of coffee per day compared to none. The associations between preconception coffee intake and SAB in the Danish study were also stronger for pregnancy losses at $\geq 8$ weeks of gestation, parallel to our results. Finally, these authors also found no association between other caffeinated beverages and SAB. Taken together, these results provide consistent evidence that pre-pregnancy coffee intake at levels $\geq 3-4$ servings per day are associated with slightly increased risk of SAB between gestation weeks 8-19.

Our results which showed a possible association between pre-pregnancy decaffeinated coffee intake and risk of SAB and no association between caffeinated tea and soda intake and $\mathrm{SAB}$ suggest that a component other than caffeine could be driving the association between coffee and SAB. This theory is supported by the one other study that assessed prepregnancy decaffeinated coffee intake and risk of SAB [2]. In this study, the adjusted odds ratio $(95 \% \mathrm{CI})$ of SAB for pre-pregnancy decaffeinated coffee intake of $0.5-1,2$, and $\geq 3$ servings per day was $1.17(0.83,1.66), 0.77(0.41,1.45)$, and $1.52(0.85,2.72)$ compared to no intake [2]. Alternatively, the association we found between pre-pregnancy decaffeinated coffee and $\mathrm{SAB}$ could be driven by women at higher risk of SAB switching from caffeinated to decaffeinated coffee due to concerns over caffeine's potential reproductive health effects. While we tried to reduce this type of bias by excluding women with a history of SAB, adjusting for many well known risk factors for SAB (e.g. age and history of infertility), and performing various sensitivity analyses, it is possible this bias could still be explaining all or part of this association.

One of the biggest limitations of our current analysis is that we lacked information on caffeine and beverage intake during early pregnancy. While it is well documented that the majority of women decrease or quit drinking coffee during the first trimester of pregnancy, women with higher pre-pregnancy coffee consumption tend to decrease their coffee 
consumption to a lesser extent [30-32]. Thus, it is likely that the women in our highest category of pre-pregnancy coffee intake were also the highest coffee consumers during early pregnancy. If early pregnancy coffee intake (e.g. between weeks 1-6) is causally related to SAB at weeks 8-19 then this could be driving the association we observed between prepregnancy intake and pregnancy loss due to the high correlation between pre-pregnancy and early first trimester pregnancy coffee consumption. However, considering many pregnancies in the US are unplanned and the most pregnancies are not recognized until 4-6 weeks gestation, the distinction between pre-pregnancy and early pregnancy consumption, while interesting from a causal standpoint, is minor in terms of clinical and public health recommendations.

Filtered coffee consists of many biologically active compounds including caffeine, polyphenols (such as chlorogenic acids), melanoidins, and trigonelline [33]. Plausible biological explanations for an association between pre-pregnancy coffee intake and risk of SAB do exist and primarily relate to coffee's effects on endogenous sex hormone metabolism. In a separate study, women with the highest coffee (but not total caffeine) intake at their last menstrual period had 32\% lower early pregnancy pregnanediol-3glucuronide levels, a hormone critical to pregnancy maintenance [34]. In two separate studies from the NHS2 cohort, higher coffee intake was associated with lower total and free luteal plasma estradiol levels [35] and higher 2-catechol estrogen metabolites, 2hydroxyestrone and 2-hydroxyestradiol [36]. Coffee has many constituents that may influence sex hormone metabolism, including caffeine. Metabolism of caffeine is catalyzed primarily by CYP1A2 enzymes, and laboratory and human studies suggest that caffeine is as an inducer of CYP1A2 activity [37]. This hepatic enzyme also plays a key role in 2-, 4-, and 16-hydroxylation of estrogen [38]. Independent of caffeine, coffee may also act as an inducer of CYP1A2 [39], potentially by polycyclic aromatic hydrocarbons produced by high brewing temperatures [40]. Laboratory evidence also suggests that caffeic acid and chlorogenic acid, two polyphenols found in coffee, can inhibit 2-catechol and 4-catechol methylation [41].

The limitations of our study are worth considering in lieu of our significant findings. Misclassification of caffeine and beverage intake is likely because diet information was only updated every four years. It is also likely that there was misclassification of total caffeine consumption as caffeine content can differ widely based on the brewing method, serving size, and portion of serving consumed [42]. However, misclassification of caffeine and beverage intake is unlikely to depend on SAB status given the prospective nature of our study. This type of non-differential misclassification would therefore tend attenuate our associations towards the null.

There is also concern that many early losses were unrecognized and that this could be differential with respect to pregnancy intention or pre-pregnancy caffeine or beverage intake. If women attempting to conceive limited their coffee intake and were more likely to recognize early miscarriages, the early miscarriage rate would be higher in the lowest coffee intake group and would bias the association between pre-pregnancy coffee intake and SAB downwards, particularly for early losses. With this in mind, it is hard to determine whether the null association we observed between coffee intake and losses at $<8$ weeks is due to this 
phenomenon or due to a lack of true biological effect. Recall errors in the self-report of spontaneous abortion are also likely as validation studies conducted in other cohorts suggest that the accuracy of recalling an SAB is 75\% [20]. Fortunately, since information on caffeine intake was assessed prior to outcomes assessment, we would not expect these recall errors to result in recall bias.

As in all observational studies, despite our adjustment and stratification for a variety of potential confounders, we cannot rule out the possibility of residual confounding including confounding by exposures of the participant's partners which were not assessed in this study. In addition, while we controlled for pre-pregnancy smoking status and conducted a sensitivity analysis in never smokers, there may be residual confounding by misreporting of smoking status and passive smoking. Our study also does not distinguish chromosomally normal from abnormal miscarriages. If pre-pregnancy caffeine or beverage intake affects chromosomally abnormal versus normal miscarriages differently, then this heterogeneity in outcome would tend to mask associations that would otherwise be evident in one of these two subgroups. Finally, while the Nurses' Health Study II cohort does not represent random samples of US women, the distribution of pre-pregnancy caffeine intake and the sources of caffeine were similar to reproductive women in the US during this same time period [43].

Despite these limitations, our study had many strengths including a large number of pregnancies, prospective design, nearly-complete follow-up over the 18 years, ability to assess specific caffeinated and decaffeinated beverages, inclusion of both planned and unplanned pregnancies, use of a validated diet assessment, and inclusion of early pregnancy losses. By studying pre-pregnancy caffeine and beverage consumption, we were also able to study an etiologically relevant exposure time window in regards to risk of SAB without concern of confounding due to nausea and food aversions.

In conclusion, we found that pre-pregnancy coffee consumption at levels $\geq 4$ servings/day was associated with increased risk of SAB, particularly at gestation weeks 8-19. The magnitude of coffee's effect on risk of SAB (3.6\% absolute difference comparing $\geq 4$ servings of coffee per day vs none) was comparable to detrimental effect of class $1 \& 2$ obesity on SAB (4.2\% absolute difference comparing women $335 \mathrm{~kg} / \mathrm{m}^{2}$ vs $18.5-24.9$ $\mathrm{kg} / \mathrm{m}^{2}$ ) [44] and the beneficial effect of consuming high amounts of supplemental folate (3.1\% absolute difference comparing women consuming no supplemental folate vs $>730$ $\mathrm{mcg} /$ day) in this cohort [45]. Since coffee represents the largest source of caffeine in the US diet, our results are consistent with current guidelines from the American Congress of Obstetricians and Gynecologists which suggest women who are pregnant and capable of pregnancy limit their caffeine intake to $<200 \mathrm{mg} /$ day [46]. Our data, however, also suggests that consumption of decaffeinated coffee could be a risk factor for spontaneous abortion. Future research is needed to disentangle the effects of caffeine versus other components of coffee that could be driving this association with pregnancy loss.

\section{Supplementary Material}

Refer to Web version on PubMed Central for supplementary material. 


\section{References}

1. Greenwood DC, Thatcher NJ, Ye J, Garrard L, Keogh G, King LG, Cade JE. Caffeine intake during pregnancy and adverse birth outcomes: a systematic review and dose-response meta-analysis. Eur J Epidemiol. 2014; 29(10):725-734. [PubMed: 25179792]

2. Fenster L, Hubbard AE, Swan SH, Windham GC, Waller K, Hiatt RA, Benowitz N. Caffeinated beverages, decaffeinated coffee, and spontaneous abortion. Epidemiology. 1997; 8(5):515-523. [PubMed: 9270953]

3. Infante-Rivard C, Fernandez A, Gauthier R, David M, Rivard GE. Fetal loss associated with caffeine intake before and during pregnancy. JAMA. 1993; 270(24):2940-2943. [PubMed: 8254854]

4. Axelsson G, Rylander R, Molin I. Outcome of pregnancy in relation to irregular and inconvenient work schedules. Br J Ind Med. 1989; 46(6):393-398. [PubMed: 2818973]

5. Savitz DA, Chan RL, Herring AH, Howards PP, Hartmann KE. Caffeine and miscarriage risk. Epidemiology. 2008; 19(1):55-62. b9. [PubMed: 18091004]

6. Wen W, Shu XO, Jacobs DR Jr, Brown JE. The associations of maternal caffeine consumption and nausea with spontaneous abortion. Epidemiology. 2001; 12(1):38-42. [PubMed: 11138817]

7. Pollack AZ, Buck Louis GM, Sundaram R, Lum KJ. Caffeine consumption and miscarriage: a prospective cohort study. Fertil Steril. 2010; 93(1):304-306. [PubMed: 19732873]

8. Wilcox AJ, Weinberg CR, Baird DD. Risk factors for early pregnancy loss. Epidemiology. 1990; 1(5):382-385. [PubMed: 2078614]

9. Tolstrup JS, Kjaer SK, Munk C, Madsen LB, Ottesen B, Bergholt T, Gronbaek M. Does caffeine and alcohol intake before pregnancy predict the occurrence of spontaneous abortion? Hum Reprod. 2003; 18(12):2704-2710. [PubMed: 14645195]

10. Hahn KA, Wise LA, Rothman KJ, Mikkelsen EM, Brogly SB, Sorensen HT, Riis AH, Hatch EE. Caffeine and caffeinated beverage consumption and risk of spontaneous abortion. Hum Reprod. 2015; 30(5):1246-1255. [PubMed: 25788567]

11. Fulgoni VL 3rd, Keast DR, Lieberman HR. Trends in intake and sources of caffeine in the diets of US adults: 2001-2010. Am J Clin Nutr. 2015; 101(5):1081-1087. [PubMed: 25832334]

12. Finer LB, Zolna MR. Shifts in intended and unintended pregnancies in the United States, 20012008. Am J Public Health. 2014; 104(Suppl 1):S43-S48. 01416. [PubMed: 24354819]

13. Dott M, Rasmussen SA, Hogue CJ, Reefhuis J. Association between pregnancy intention and reproductive-health related behaviors before and after pregnancy recognition, National Birth Defects Prevention Study, 1997-2002. Matern Child Health J. 2010; 14(3):373-381. [PubMed: 19252975]

14. Mohllajee AP, Curtis KM, Morrow B, Marchbanks PA. Pregnancy intention and its relationship to birth and maternal outcomes. Obstet Gynecol. 2007; 109(3):678-686. [PubMed: 17329520]

15. Willett, WC., Lenart, E. Chapter 6: Reproducibility and validity of Food Frequency Questionnaires. In: Willett, WC., editor. Nutritional Epidemiology. Second. New York, New York: Oxford University Press; 1998.

16. Rimm EB, Giovannucci EL, Stampfer MJ, Colditz GA, Litin LB, Willett WC. Reproducibility and validity of an expanded self-administered semiquantitative food frequency questionnaire among male health professionals. Am J Epidemiol. 1992; 135(10):1114-1126. discussion 1127-1136. [PubMed: 1632423]

17. U.S. Department of Agriculture Agricultural Research Service. USDA National Nutrient Database for Standard Reference, Release 25. 2012 http://www.ars.usda.gov/ba/bhnrc/ndl.

18. Salvini S, Hunter DJ, Sampson L, Stampfer MJ, Colditz GA, Rosner B, Willett WC. Food-based validation of a dietary questionnaire: the effects of week-to-week variation in food consumption. Int J Epidemiol. 1989; 18(4):858-867. [PubMed: 2621022]

19. Olson JE, Shu XO, Ross JA, Pendergrass T, Robison LL. Medical record validation of maternally reported birth characteristics and pregnancy-related events: a report from the Children's Cancer Group. Am J Epidemiol. 1997; 145(1):58-67. [PubMed: 8982023]

20. Wilcox AJ, Horney LF. Accuracy of spontaneous abortion recall. Am J Epidemiol. 1984; 120(5): 727-733. [PubMed: 6541871] 
21. Kristensen P, Irgens LM. Maternal reproductive history: a registry based comparison of previous pregnancy data derived from maternal recall and data obtained during the actual pregnancy. Acta Obstet Gynecol Scand. 2000; 79(6):471-477. [PubMed: 10857871]

22. Rimm EB, Stampfer MJ, Colditz GA, Chute CG, Litin LB, Willett WC. Validity of self-reported waist and hip circumferences in men and women. Epidemiology. 1990; 1(6):466-473. [PubMed: 2090285]

23. Wolf AM, Hunter DJ, Colditz GA, Manson JE, Stampfer MJ, Corsano KA, Rosner B, Kriska A, Willett WC. Reproducibility and validity of a self-administered physical activity questionnaire. Int J Epidemiol. 1994; 23(5):991-999. [PubMed: 7860180]

24. Durrleman S, Simon R. Flexible regression models with cubic splines. Stat Med. 1989; 8(5):551561. [PubMed: 2657958]

25. Weinberg CR. Toward a clearer definition of confounding. Am J Epidemiol. 1993; 137(1):1-8. [PubMed: 8434568]

26. Howards PP, Schisterman EF, Heagerty PJ. Potential confounding by exposure history and prior outcomes: an example from perinatal epidemiology. Epidemiology. 2007; 18(5):544-551. [PubMed: 17879426]

27. Kost K, Forrest JD. Intention status of U.S. births in 1988: differences by mothers' socioeconomic and demographic characteristics. Fam Plann Perspect. 1995; 27(1):11-17. [PubMed: 7720847]

28. Glei DA. Measuring contraceptive use patterns among teenage and adult women. Fam Plann Perspect. 1999; 31(2):73-80. [PubMed: 10224545]

29. Chen LW, Wu Y, Neelakantan N, Chong MF, Pan A, van Dam RM. Maternal caffeine intake during pregnancy and risk of pregnancy loss: a categorical and dose-response meta-analysis of prospective studies. Public Health Nutr. 2016; 19(7):1233-1244. [PubMed: 26329421]

30. Lawson CC, LeMasters GK, Wilson KA. Changes in caffeine consumption as a signal of pregnancy. Reprod Toxicol. 2004; 18(5):625-633. [PubMed: 15219624]

31. Cnattingius S, Signorello LB, Anneren G, Clausson B, Ekbom A, Ljunger E, Blot WJ, McLaughlin JK, Petersson G, Rane A, Granath F. Caffeine intake and the risk of first-trimester spontaneous abortion. N Engl J Med. 2000; 343(25):1839-1845. [PubMed: 11117975]

32. Hook EB. Dietary cravings and aversions during pregnancy. Am J Clin Nutr. 1978; 31(8):13551362. [PubMed: 277064]

33. Ludwig IA, Clifford MN, Lean ME, Ashihara H, Crozier A. Coffee: biochemistry and potential impact on health. Food Funct. 2014; 5(8):1695-1717. [PubMed: 24671262]

34. Lawson CC, LeMasters GK, Levin LS, Liu JH. Pregnancy hormone metabolite patterns, pregnancy symptoms, and coffee consumption. Am J Epidemiol. 2002; 156(5):428-437. [PubMed: 12196312]

35. Kotsopoulos J, Eliassen AH, Missmer SA, Hankinson SE, Tworoger SS. Relationship between caffeine intake and plasma sex hormone concentrations in premenopausal and postmenopausal women. Cancer. 2009; 115(12):2765-2774. [PubMed: 19384973]

36. Sisti JS, Hankinson SE, Caporaso NE, Gu F, Tamimi RM, Rosner B, Xu X, Ziegler R, Eliassen AH. Caffeine, Coffee, and Tea Intake and Urinary Estrogens and Estrogen Metabolites in Premenopausal Women. Cancer Epidemiol Biomarkers Prev. 2015; 24(8):1174-1183. [PubMed: 26063478]

37. Butler MA, Iwasaki M, Guengerich FP, Kadlubar FF. Human cytochrome P-450PA (P-450IA2), the phenacetin O-deethylase, is primarily responsible for the hepatic 3-demethylation of caffeine and N-oxidation of carcinogenic arylamines. Proc Natl Acad Sci U S A. 1989; 86(20):7696-7700. [PubMed: 2813353]

38. Lee AJ, Cai MX, Thomas PE, Conney AH, Zhu BT. Characterization of the oxidative metabolites of 17 beta-estradiol and estrone formed by 15 selectively expressed human cytochrome p450 isoforms. Endocrinology. 2003; 144(8):3382-3398. [PubMed: 12865317]

39. Djordjevic N, Ghotbi R, Bertilsson L, Jankovic S, Aklillu E. Induction of CYP1A2 by heavy coffee consumption in Serbs and Swedes. Eur J Clin Pharmacol. 2008; 64(4):381-385. [PubMed: 18157525] 
40. Vakharia DD, Liu N, Pause R, Fasco M, Bessette E, Zhang QY, Kaminsky LS. Effect of metals on polycyclic aromatic hydrocarbon induction of CYP1A1 and CYP1A2 in human hepatocyte cultures. Toxicol Appl Pharmacol. 2001; 170(2):93-103. [PubMed: 11162773]

41. Zhu BT, Wang P, Nagai M, Wen Y, Bai HW. Inhibition of human catechol-O-methyltransferase (COMT)-mediated O-methylation of catechol estrogens by major polyphenolic components present in coffee. J Steroid Biochem Mol Biol. 2009; 113(1-2):65-74. [PubMed: 19095062]

42. Bracken MB, Triche E, Grosso L, Hellenbrand K, Belanger K, Leaderer BP. Heterogeneity in assessing self-reports of caffeine exposure: implications for studies of health effects. Epidemiology. 2002; 13(2):165-171. [PubMed: 11880757]

43. Frary CD, Johnson RK, Wang MQ. Food sources and intakes of caffeine in the diets of persons in the United States. J Am Diet Assoc. 2005; 105(1):110-113. [PubMed: 15635355]

44. Gaskins AJ, Rich-Edwards JW, Colaci DS, Afeiche MC, Toth TL, Gillman MW, Missmer SA, Chavarro JE. Prepregnancy and early adulthood body mass index and adult weight change in relation to fetal loss. Obstet Gynecol. 2014; 124(4):662-669. [PubMed: 25198273]

45. Gaskins AJ, Rich-Edwards JW, Hauser R, Williams PL, Gillman MW, Ginsburg ES, Missmer SA, Chavarro JE. Maternal prepregnancy folate intake and risk of spontaneous abortion and stillbirth. Obstet Gynecol. 2014; 124(1):23-31. [PubMed: 24901281]

46. The American Congress of Obstetricia ns and Gynecologists (ACOG) Committee Opinion No. 462: Moderate caffeine consumption during pregnancy. Obstet Gynecol. 2010; 116(2 Pt 1):467468. [PubMed: 20664420] 


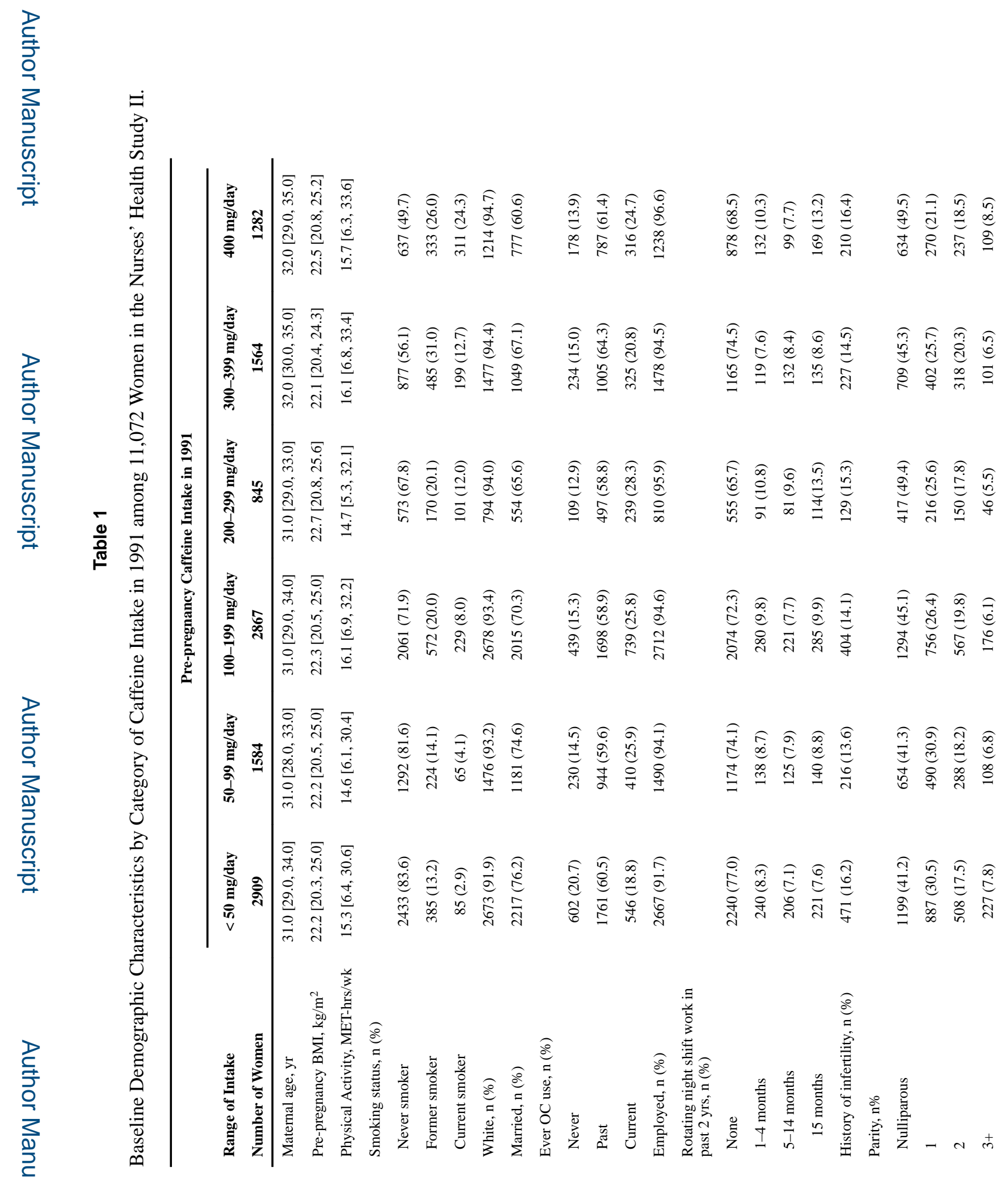

Eur J Nutr. Author manuscript; available in PMC 2019 February 01. 


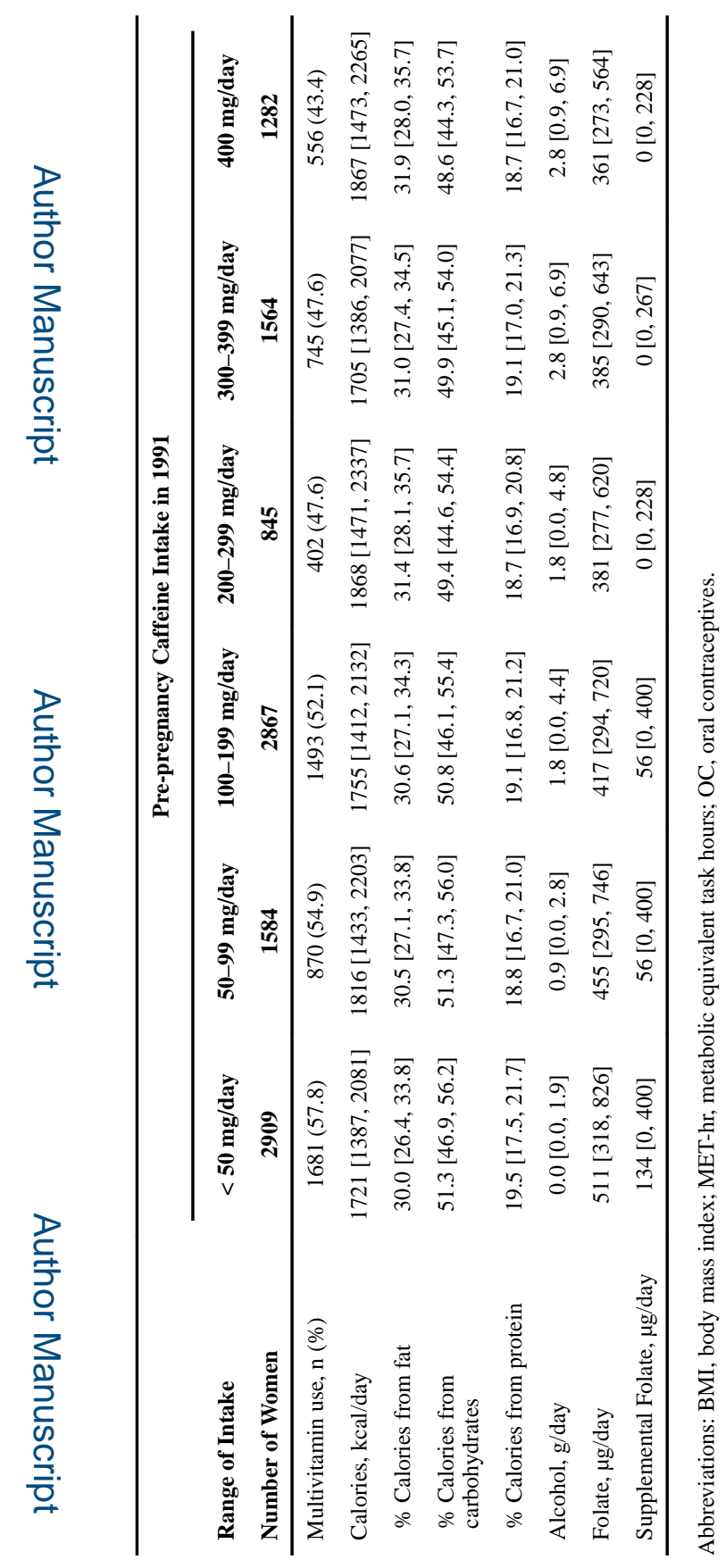

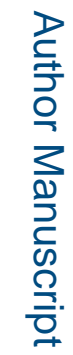




\section{Table 2}

Pre-pregnancy Caffeine and Caffeinated and Decaffeinated Beverage Intake and Relative Risks of Spontaneous Abortion among 11,072 Women (15,950 Pregnancies) in the Nurses' Health Study II.

\begin{tabular}{|c|c|c|c|c|}
\hline Categories of Intake (Range) & Cases/Total & $\%$ & $\begin{array}{c}\text { Age, Year, \& Energy- } \\
\text { Adjusted RR }(95 \% \text { CI })^{a}\end{array}$ & $\begin{array}{l}\text { Multivariate-Adjusted } \\
\quad \operatorname{RR}(95 \% \text { CI })^{b}\end{array}$ \\
\hline \multicolumn{5}{|l|}{ Caffeine } \\
\hline$<50 \mathrm{mg} /$ day & $759 / 4533$ & 16.7 & 1.00 (Ref) & $1.00(\mathrm{Ref})$ \\
\hline $50-99 \mathrm{mg} /$ day & $333 / 2192$ & 15.2 & $0.93(0.83,1.05)$ & $0.92(0.82,1.03)$ \\
\hline $100-199 \mathrm{mg} /$ day & $705 / 4115$ & 17.1 & $1.01(0.92,1.11)$ & $0.99(0.91,1.09)$ \\
\hline $200-299 \mathrm{mg} /$ day & $185 / 1091$ & 17.0 & $0.99(0.86,1.14)$ & $0.96(0.83,1.11)$ \\
\hline $300-399 \mathrm{mg} /$ day & $428 / 2302$ & 18.6 & $1.06(0.95,1.17)$ & $1.04(0.93,1.16)$ \\
\hline$\geq 400 \mathrm{mg} /$ day & $346 / 1717$ & 20.2 & $1.14(1.02,1.28)$ & $1.11(0.98,1.25)$ \\
\hline$P$ for trend & & & 0.008 & 0.05 \\
\hline \multicolumn{5}{|l|}{ Total Coffee } \\
\hline Per 1 serving/day & & & $1.04(1.02,1.06)$ & $1.04(1.01,1.06)$ \\
\hline Never & $1065 / 6633$ & 16.1 & 1.00 (Ref) & 1.00 (Ref) \\
\hline$<1$ serving per day & $347 / 2145$ & 16.2 & $1.01(0.91,1.13)$ & $1.02(0.92,1.14)$ \\
\hline 1 serving per day & $317 / 1758$ & 18.0 & $1.09(0.98,1.22)$ & $1.11(0.99,1.24)$ \\
\hline $2-3$ servings per day & $782 / 4281$ & 18.3 & $1.08(1.00,1.18)$ & $1.09(1.00,1.19)$ \\
\hline$\geq 4$ servings per day & $245 / 1133$ & 21.6 & $1.21(1.07,1.37)$ & $1.20(1.06,1.36)$ \\
\hline$P$ for trend & & & 0.002 & 0.004 \\
\hline \multicolumn{5}{|l|}{ Caffeinated Coffee } \\
\hline Per 1 serving/day & & & $1.04(1.01,1.07)$ & $1.04(1.01,1.06)$ \\
\hline Never & $1151 / 7117$ & 16.2 & 1.00 (Ref) & 1.00 (Ref) \\
\hline$<1$ serving per day & $490 / 2883$ & 17.0 & $1.05(0.95,1.15)$ & $1.06(0.96,1.16)$ \\
\hline 1 serving per day & $404 / 2254$ & 17.9 & $1.08(0.98,1.20)$ & $1.09(0.98,1.20)$ \\
\hline $2-3$ servings per day & $568 / 3035$ & 18.7 & $1.10(1.00,1.20)$ & $1.09(1.00,1.20)$ \\
\hline$\geq 4$ servings per day & $143 / 661$ & 21.6 & $1.23(1.06,1.42)$ & $1.20(1.03,1.41)$ \\
\hline$P$ for trend & & & 0.003 & 0.01 \\
\hline \multicolumn{5}{|l|}{ Decaffeinated Coffee } \\
\hline Per 1 serving/day & & & $1.04(0.99,1.10)$ & $1.04(0.98,1.09)$ \\
\hline Never & $1797 / 10690$ & 16.8 & 1.00 (Ref) & 1.00 (Ref) \\
\hline $1-4$ servings per month & $431 / 2573$ & 16.8 & $0.98(0.89,1.08)$ & $0.97(0.88,1.07)$ \\
\hline $2-6$ servings per week & $237 / 1175$ & 20.2 & $1.19(1.05,1.34)$ & $1.21(1.07,1.36)$ \\
\hline$\geq 1$ serving per day & $291 / 1512$ & 19.3 & $1.06(0.95,1.18)$ & $1.06(0.95,1.18)$ \\
\hline$P$ for trend & & & 0.04 & 0.04 \\
\hline \multicolumn{5}{|l|}{ Caffeinated Tea } \\
\hline Per 1 serving/day & & & $0.99(0.95,1.03)$ & $0.98(0.95,1.02)$ \\
\hline Never & $1106 / 6241$ & 17.7 & 1.00 (Ref) & 1.00 (Ref) \\
\hline$<1$ serving per day & $1085 / 6311$ & 17.2 & $1.01(0.94,1.09)$ & $0.99(0.92,1.06)$ \\
\hline 1 serving per day & $305 / 1817$ & 16.8 & $1.02(0.91,1.14)$ & $1.00(0.89,1.12)$ \\
\hline$\geq 2$ servings per day & $260 / 1581$ & 16.5 & $0.98(0.87,1.11)$ & $0.96(0.85,1.09)$ \\
\hline
\end{tabular}




\begin{tabular}{|c|c|c|c|c|}
\hline Categories of Intake (Range) & Cases/Total & $\%$ & $\begin{array}{c}\text { Age, Year, \& Energy- } \\
\text { Adjusted RR }(95 \% \text { CI })^{a}\end{array}$ & $\begin{array}{l}\text { Multivariate-Adjusted } \\
\text { RR }(95 \% \text { CI })^{b}\end{array}$ \\
\hline$P$ for trend & & & 0.84 & 0.60 \\
\hline \multicolumn{5}{|l|}{ Caffeinated Soda } \\
\hline Per 1 serving/day & & & $1.04(1.00,1.07)$ & $1.02(0.99,1.06)$ \\
\hline Never & $748 / 4230$ & 17.7 & 1.00 (Ref) & 1.00 (Ref) \\
\hline$<1$ serving per day & $1256 / 7437$ & 16.9 & $1.02(0.94,1.11)$ & $1.00(0.92,1.08)$ \\
\hline 1 serving per day & $403 / 2341$ & 17.2 & $1.06(0.95,1.18)$ & $1.02(0.91,1.14)$ \\
\hline$\geq 2$ servings per day & $349 / 1942$ & 18.0 & $1.12(1.00,1.26)$ & $1.06(0.94,1.19)$ \\
\hline$P$ for trend & & & 0.04 & 0.26 \\
\hline \multicolumn{5}{|l|}{ Decaffeinated Soda } \\
\hline Per 1 serving/day & & & $0.97(0.93,1.02)$ & $0.97(0.93,1.01)$ \\
\hline Never & $895 / 4670$ & 19.2 & 1.00 (Ref) & 1.00 (Ref) \\
\hline $1-4$ servings per month & $727 / 4309$ & 16.9 & $0.95(0.87,1.04)$ & $0.94(0.86,1.03)$ \\
\hline $2-6$ servings per week & $716 / 4345$ & 16.5 & $0.95(0.87,1.04)$ & $0.95(0.87,1.04)$ \\
\hline 1 serving per day & $242 / 1533$ & 15.8 & $0.92(0.81,1.05)$ & $0.92(0.81,1.04)$ \\
\hline$\geq 2$ servings per day & $176 / 1093$ & 16.1 & $0.93(0.80,1.07)$ & $0.90(0.78,1.04)$ \\
\hline$P$ for trend & & & 0.26 & 0.16 \\
\hline
\end{tabular}

Abbreviations: RR, relative risk; CI, confidence interval.

Analyses run using a log-binomial generalized linear model with an exchangeable working correlation structure to compute relative risk estimates. Tests for linear trend were conducted by using the median values in each category as a continuous variable.

${ }^{a}$ Adjusted for age (continuous), total energy intake (continuous), and year (continuous).

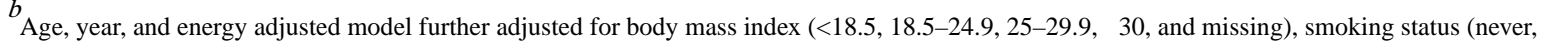
former, current, and missing), physical activity (<3 MET-h/wk, 3-8.9 MET-h/wk, 9-17.9 MET-h/wk, 18-26.9 MET-h/wk, 27-41.9 MET-h/wk, >42 MET-h/wk, and missing), history of infertility (no, yes, and missing), marital status (married, not married), employment status (yes, no), duration of rotating shift work in past 2 years (none, 1-4 months, 5-14 months, $\geq 15$ months), race (white, other), alcohol intake (quintiles), supplemental folate intake (quartiles). All caffeinated beverages were adjusted for one another. Decaf coffee and soda intake were further adjusted for caffeinated coffee intake. 


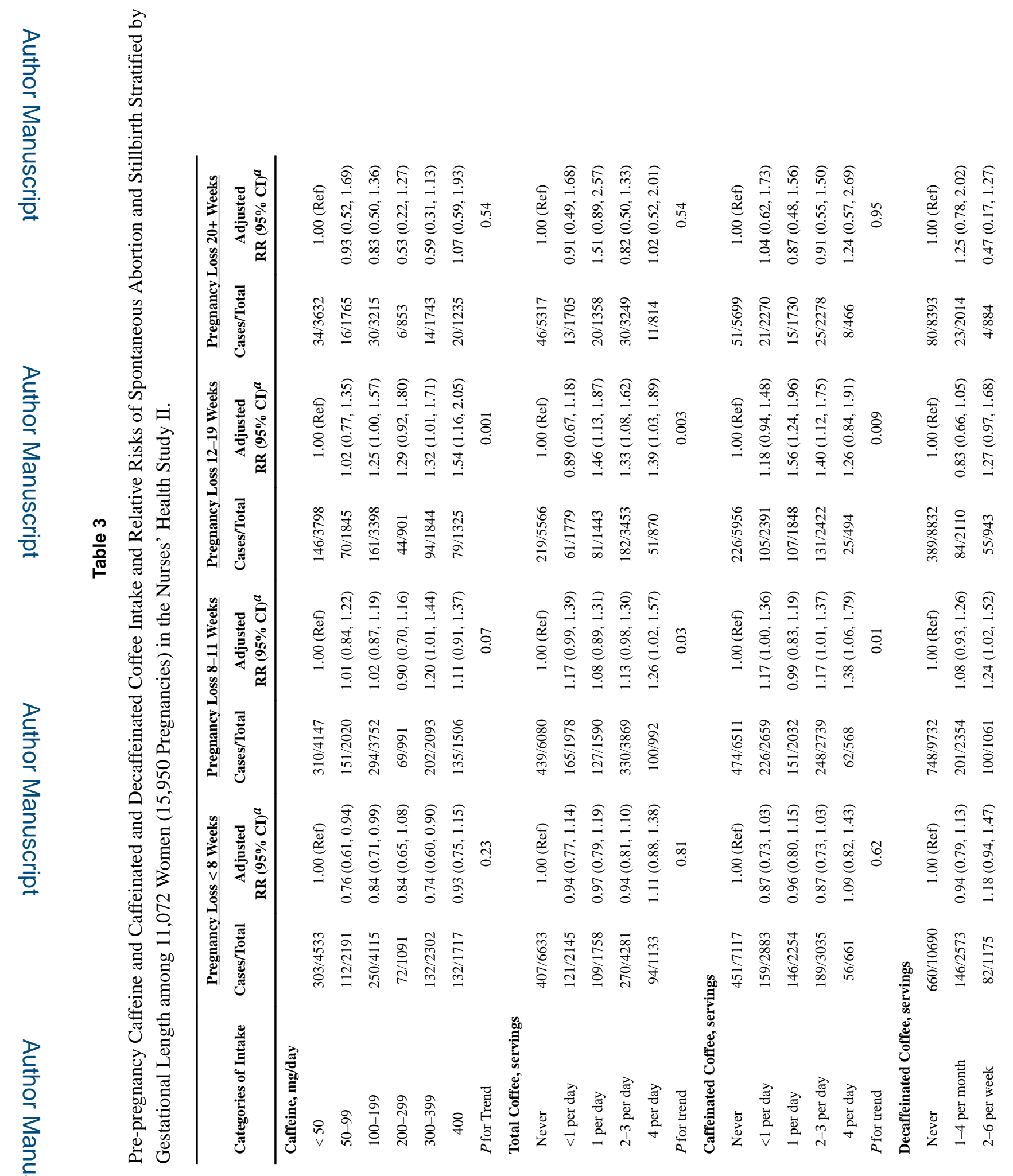

Eur J Nutr. Author manuscript; available in PMC 2019 February 01. 


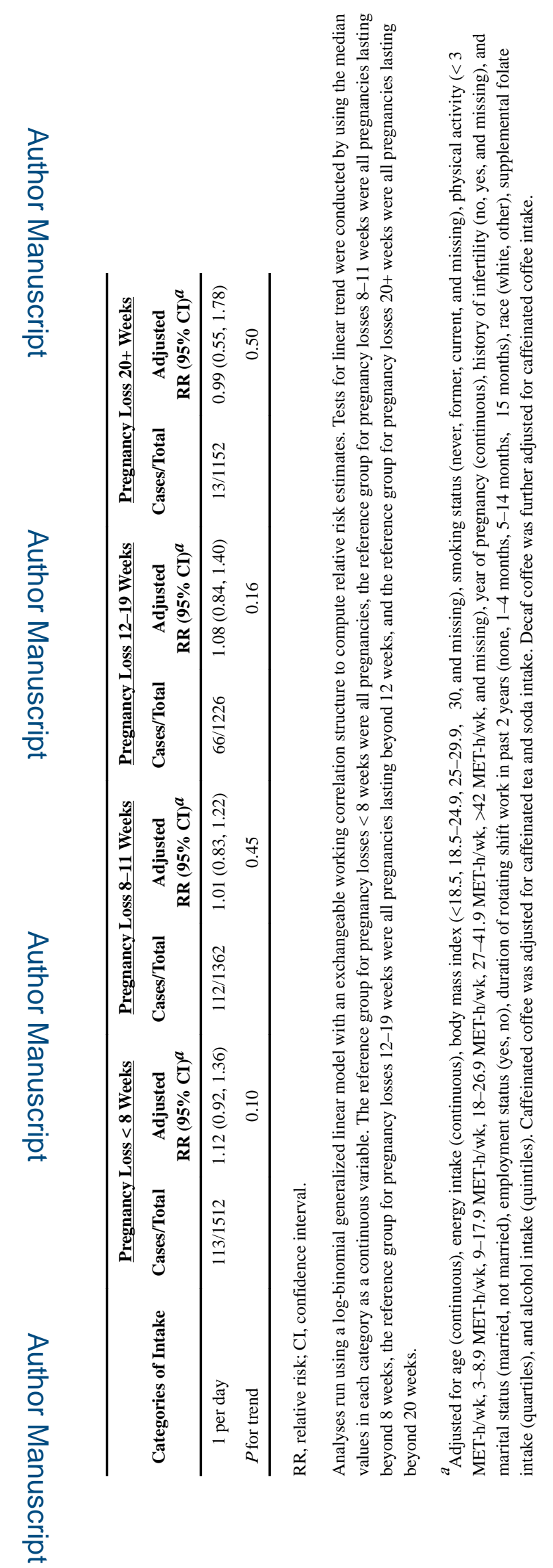

Eur J Nutr. Author manuscript; available in PMC 2019 February 01. 